\title{
Quantity of HLA-C surface expression and licensing of KIR2DL+ natural killer cells
}

\author{
Hojjatollah Nozad Charoudeh • Laurent Schmied • \\ Asensio Gonzalez • Grzegorz Terszowski - Karol Czaja • \\ Karin Schmitter • Laura Infanti • Andreas Buser • \\ Martin Stern
}

Received: 22 March 2012 / Accepted: 16 June 2012 / Published online: 7 July 2012

(C) Springer-Verlag 2012

\begin{abstract}
Natural killer (NK) cells require interaction of inhibitory surface receptors with human leukocyte antigen (HLA) ligands during development to acquire functional competence in a process termed "licensing." The quantity of HLA required for this process is unknown. Two polymorphisms affecting HLA-C surface expression (rs9264942 and rs67384697) have recently been identified, and shown to influence progression of HIV infection. We typed a cohort of healthy donors for the two HLA-C-related polymorphisms, KIR2DL1 and KIR2DL3, and their respective $H L A-C$ ligands and analyzed how HLA ligands influenced licensing status of killer cell immunoglobulin-like receptor (KIR)+ NK cells in terms of degranulation and cytokine production in response to HLA-deficient target cells. The presence of respective HLA class I ligands increased the function of KIR2DL1+ and KIR2DL3 + NK cells in a dosedependent manner. In contrast, neither of the HLA-C-related polymorphisms nor the quantity of cell surface HLA-C had any significant effect on NK cell function. Interestingly, HLA-Cw7 - an HLA-C allele with low surface expressionlicensed KIR2DL3+ NK cells more strongly than any other KIR2DL3 ligand. The quantity of cell surface HLA-C does not appear to influence licensing of NK cells, and the HLA-Crelated polymorphisms presumably influence HIV progression through factors unrelated to NK cell education.
\end{abstract}

\footnotetext{
H. N. Charoudeh • L. Schmied • A. Gonzalez - G. Terszowski •

K. Czaja $\cdot$ K. Schmitter $\cdot$ M. Stern $(\bowtie)$

Immunotherapy Laboratory, Department of Biomedicine,

University Hospital Basel,

Hebelstrasse 20,

4031 Basel, Switzerland

e-mail: sternm@uhbs.ch

L. Infanti $\cdot$ A. Buser

Blood Bank, University Hospital Basel,

Basel, Switzerland
}

Keywords Natural killer cells $\cdot$ Killer cell immunoglobulinlike receptors $\cdot$ HLA $\cdot$ rs9264942 $\cdot$ rs67384697

\section{Introduction}

Natural killer (NK) cells are a subset of lymphocytes involved in the defense against viral infection and malignant transformation. Upon target recognition, NK cells synthesize and secrete cytokines and lyse target cells without the need for pre-activation (Lanier 2005). NK cell function is regulated by the integration of signals derived from activating and inhibitory receptors. Among inhibitory receptors, killer cell immunoglobulin-like receptors (KIR) - which bind to class I human leukocyte antigens (HLA) - play a pivotal role in discriminating normal from pathologic tissue (Biassoni et al. 2003). The inhibitory signal derived from the KIR/HLA interaction renders NK cells tolerant towards autologous tissue, whereas cells lacking HLA class I may trigger an NK cell response resulting in target cell lysis.

Recent evidence has pointed out that this function is acquired during NK cell development in a process termed "licensing": only NK cells expressing inhibitory receptors for self-HLA obtain the functional competence to respond to the lack of HLA ligands on a target cell (Anfossi et al. 2006; Kim et al. 2008; Yokoyama and Kim 2006). In contrast, NK cells whose inhibitory receptors did not interact with their cognate ligands during development remain unlicensed (Brodin and Hoglund 2008). A previous study analyzing the interaction of the KIR3DL1 receptor with its ligandHLA with the Bw4 motif-showed that NK cells from donors carrying two Bw4 alleles showed higher levels of licensing compared to NK cells from donors carrying no or only one Bw4 allele (Kim et al. 2008). As a further potential variable in the equation, HLA antigens are expressed on the cell surface at varying quantities. A single nucleotide 
polymorphism (SNP; rs9264942) located $35 \mathrm{~kb}$ upstream of the HLA-C gene - termed HLA-C - 35-was recently identified to associate with the abundance of cell surface HLA-C (Thomas et al. 2009). HLA-C -35 has been demonstrated to be a major factor governing viral load and progression of human immunodeficiency virus (HIV) infection. "Set point" viral load in untreated patients was lower, and progression of HIV was delayed in patients carrying $\mathrm{C}$ alleles - associated with higher amounts of cell surface HLA-C - compared to carriers of T alleles (Fellay et al. 2007; Pereyra et al. 2010). Following this, a novel single nucleotide deletion polymorphism in the $3^{\prime}$ untranslated region (UTR) of HLA-C (rs67384697) has been shown to influence binding of the microRNA hsa-miR-148, and thereby associated with HLAC surface expression (Kulkarni et al. 2011). Similar to HLA$C-35$, this single nucleotide polymorphism was shown to associate with HIV set point viral loads.

As NK cells participate in the control of HIV replication (Alter et al. 2011), we hypothesized that the association of $H L A-C-35$ and the $3^{\prime}$ UTR HLA-C deletion SNP with HIV progression might be due to a role for the quantity of HLA-C in the NK cell licensing process. To address the question experimentally, we assessed in a large cohort of healthy donors both HLA-C-related polymorphisms and HLA-C surface expression on lymphocytes. We correlated these data to the functional competence of NK cells in terms of cytokine production and degranulation after exposure to class I negative tumor cells. NK cell function was compared in NK cell subsets with or without expression of the inhibitory KIR receptors KIR2DL1 and KIR2DL3, which recognize mutually exclusive subsets of HLA-C ligands termed $\mathrm{C} 1$ and $\mathrm{C} 2$ (Winter et al. 1998). The HLA C1 group includes HLA Cw antigens carrying asparagine at position 80 (e.g., HLA Cw1, $\mathrm{Cw} 3, \mathrm{Cw} 7$, and $\mathrm{Cw} 8$ ), whereas the HLA C2 group includes HLA $\mathrm{Cw}$ antigens carrying lysine at position 80 (e.g., HLA Cw2, Cw4, Cw5, and Cw6; Winter and Long 1997).

\section{Materials and methods}

Antibodies and flow cytometry

The following mAbs were used: anti-CD3 Pacific blue (OKT3, eBioscience), anti-CD56 PE-Cy7 (HCD56, Biolegend), anti-CD107a PE (clone H4A3, BD), anti-IFN- $\gamma$ PE (clone B27, BD), anti-KIR2DL1 FITC (clone 143211, R\&D), anti-KIR2DL3 APC (clone 180701, R\&D), and the panHLA-C antibody DT9 (kindly provided by Mary Carrington, National Institute of Health, Bethesda, USA) which was used in conjunction with goat anti-mouse IgG2b PE (Southern Biotech).

To evaluate HLA-C surface expression, we used QuantumTM R-PE MESF Kit (Polysciences, Inc., Warrington,
USA) according to the manufacturer's instructions. The mean fluorescence intensity of the five bead populations was used to calculate a calibration curve by plotting the MFI for each population against its known units of molecules of equivalent soluble fluorophores (MESF). Staining intensity of DT9 is therefore expressed as MESF units.

Samples were acquired on a DAKO CyAn ADP ninecolor flow cytometer (Beckman Coulter). For all analyses of NK cell subsets, we gated on the CD56+/CD3 - subset. For quantification of HLA-C expression, we gated on total lymphocytes. Fluorescence-activated cell sorting (FACS) plots were analyzed with FlowJo software version 9.2.

\section{CD107a and IFN- $\gamma$ assay}

Peripheral blood mononuclear cells (PBMCs) from healthy donors were collected under an ethical committee-approved protocol, isolated by density gradient centrifugation, and cryopreserved. After thawing, cells were cultured overnight in the presence of $150 \mathrm{U} / \mathrm{mL}$ recombinant human IL-2 (Proleukin, Novartis), after which PBMCs $(0.5 \times 10 \mathrm{e} 6)$ were mixed with the HLA-deficient 721.221 cell line at a ratio of $5: 1$ in a final volume of $200 \mu \mathrm{L}$ in flat-bottom 96-well plates and incubated for $5 \mathrm{~h}$ at $37^{\circ} \mathrm{C} / 5 \% \mathrm{CO}_{2}$. NK cell response to 721.221 was measured in terms of degranulation (CD107a surface expression) and cytokine production (intracellular cytokine staining for IFN- $\gamma$; Alter et al. 2004).

Anti-CD107a PE was added to wells at the beginning of the incubation. For the IFN- $\gamma$ assay, brefeldin A (Golgi Plug, BD Biosciences) was added after $1 \mathrm{~h}$ of incubation at a concentration of 1:200, after which cells remained incubated for another $4 \mathrm{~h}$. For intracellular staining of IFN- $\gamma$, cells were permeabilized with Cytofix/Cytoperm (BD) and washed with BD Perm/Wash buffer. As positive control, phorbol 12-myristate 13-acetate, and a calcium ionophore (ionomycin) were used.

To assess the magnitude of licensing conferred by KIR2DL1 and KIR2DL3, frequencies of IFN- $\gamma+$ and $\mathrm{CD} 107 \mathrm{a}+$ cells were assessed in CD56+/CD3-/KIR + and CD56+/CD3-/KIR - subsets. Ratios of IFN- $\gamma+$ cells and $\mathrm{CD} 107 \mathrm{a}+$ cells within KIR+ and KIR- NK cells were calculated to estimate the alteration in functional competence derived by the expression of the respective KIR receptor (Fig. 1). We then compared the effect of the presence or absence of HLA C1/C2 group ligands, the $H L A-C-35$ and 3' UTR HLA-C polymorphisms, and the amount of cell surface HLA-C had on these licensing ratios.

\section{Genotyping and quantitative PCR}

The HLA-C -35 SNP was genotyped using a commercial ABI TaqMan allelic discrimination kit on the ABI7500 Sequence Detection System according to manufacturer's 
Fig. 1 Increased functional capacity of NK cells expressing inhibitory KIR2D receptors. After gating on CD56+/CD3NK cells, CD107a expression induced by co-incubation with 721.221 tumor cells is compared in NK cells which do or do not carry the inhibitory KIR2DL1 receptor. The ratio of $\mathrm{CD} 107 \mathrm{a}$ expression in KIR2DL1+ and KIR2DL1- NK cells (termed "licensing ratio") quantifies the increase in functional competence derived from expression of KIR2DL1. IFN- $\gamma$ production and the receptor KIR2DL3 were analyzed in the same fashion
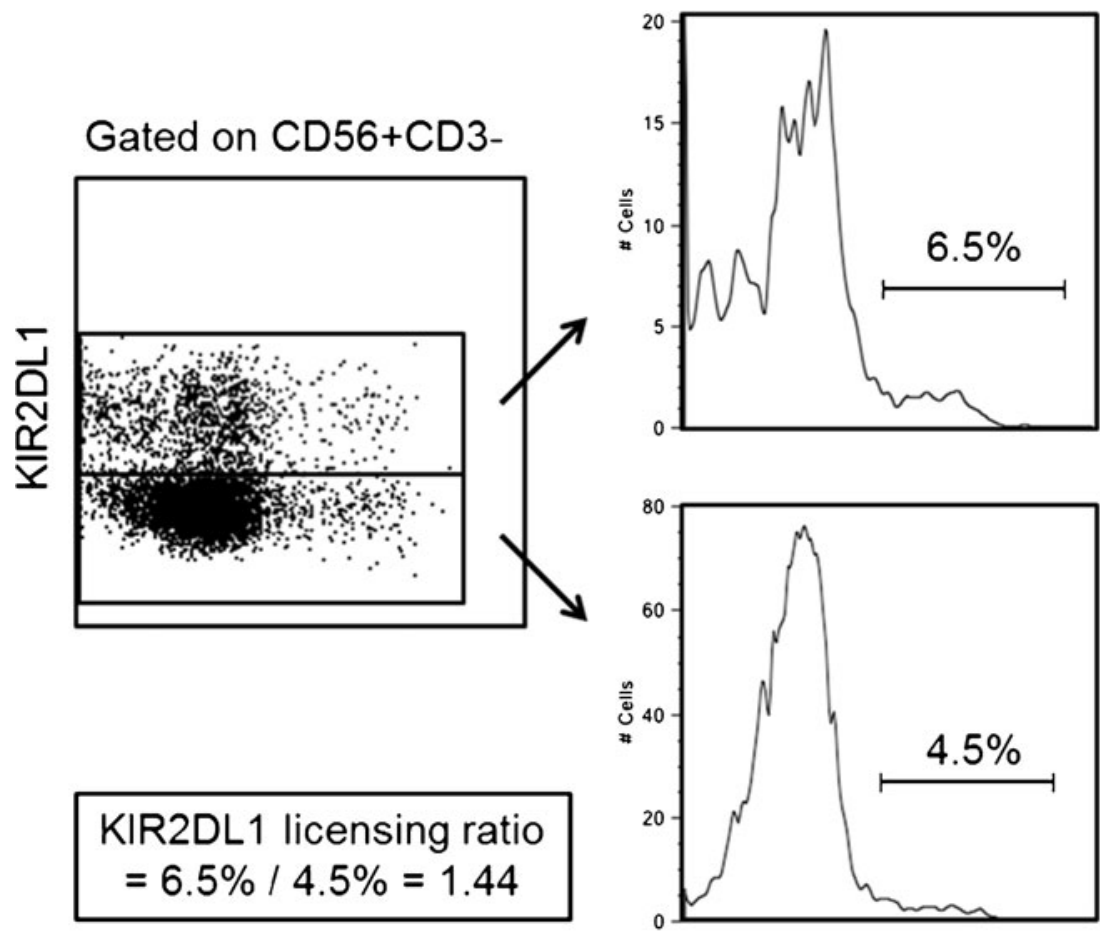

guidelines. The rs67384697 polymorphism located within the 3' UTR was typed by direct sequencing (Kulkarni et al.
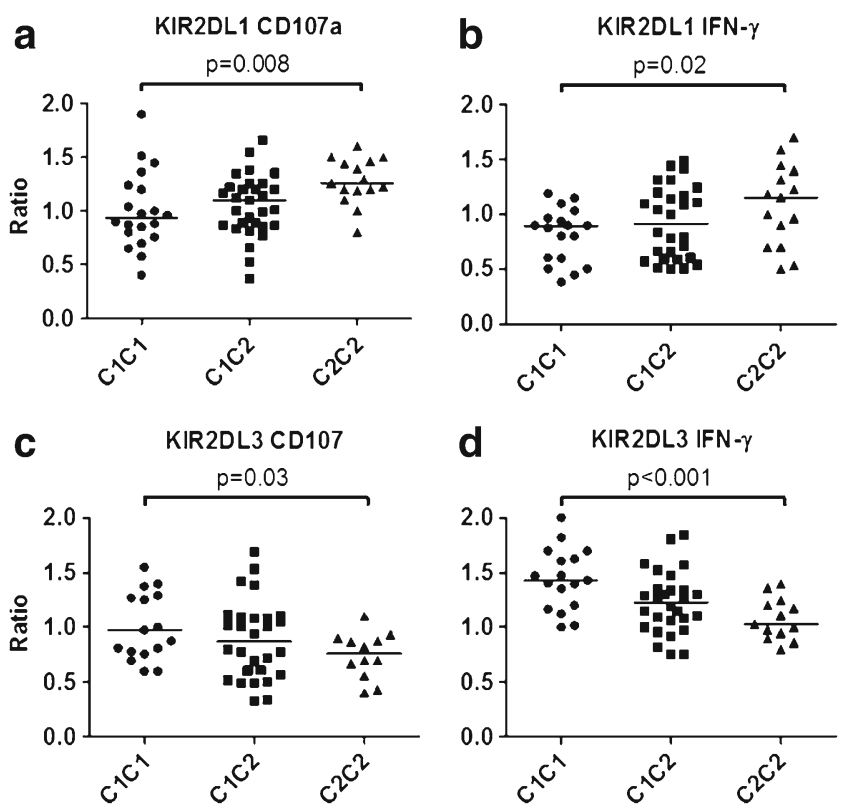

Fig. 2 Degranulation and cytokine production of KIR2DL1+ and KIR2DL3 NK+ cells in relation to the number of KIR ligands. CD107a and IFN expression are evaluated in NK cells derived from 66 donors after co-incubation with the HLA-deficient 721.221 cell line. CD107a expression and IFN- $\gamma$ production of KIR2DL1+ NK cells significantly increase with growing numbers of $\mathrm{C} 2$ ligands (a and $\mathbf{b})$. CD107a expression and IFN- $\gamma$ production of KIR2DL3+ NK cells significantly increase with growing number of $\mathrm{C} 1$ ligands (c and $\mathbf{d})$
CD107a

2011). Genotyping for HLA-C1/C2 group KIR ligands and for the inhibitory KIR2DL1 and KIR2DL3 was performed using previously established sequence-specific primer protocols (Alves et al. 2009; Frohn et al. 1998). HLA-C was
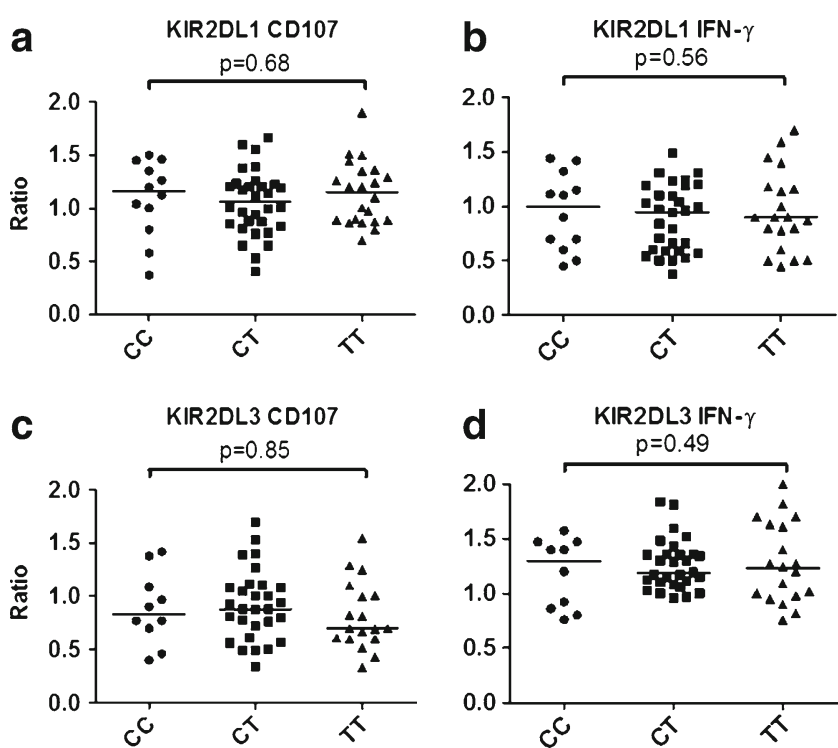

Fig. 3 Correlation of degranulation and cytokine production of KIR2DL1 and KIR2DL3 NK subsets with the $H L A-C-35$ polymorphism. The $H L A-C-35$ genotype does not significantly influence NK licensing of KIR2DL1+ and KIR2DL3+ NK cells as assessed by CD107a expression and IFN- $\gamma$ production after exposure to the HLA class I-negative cell line 721.221 
Fig. 4 Correlation of HLA-C expression HLA-C -35 genotype and NK cell function. The $H L A-C-35$ genotype influences the expression of HLA-C as detected by the DT9 antibody in flow cytometry (panel a). A trend towards higher expression of HLA-C is detected for patients carrying the deletetion variant in the 3'UTR of HLA-C (panel b). In contrast, no significant correlation was detected between CD107a licensing ratios (panel c) and IFN- $\gamma$ licensing ratios (panel d), respectively, and surface expression of HLA-C
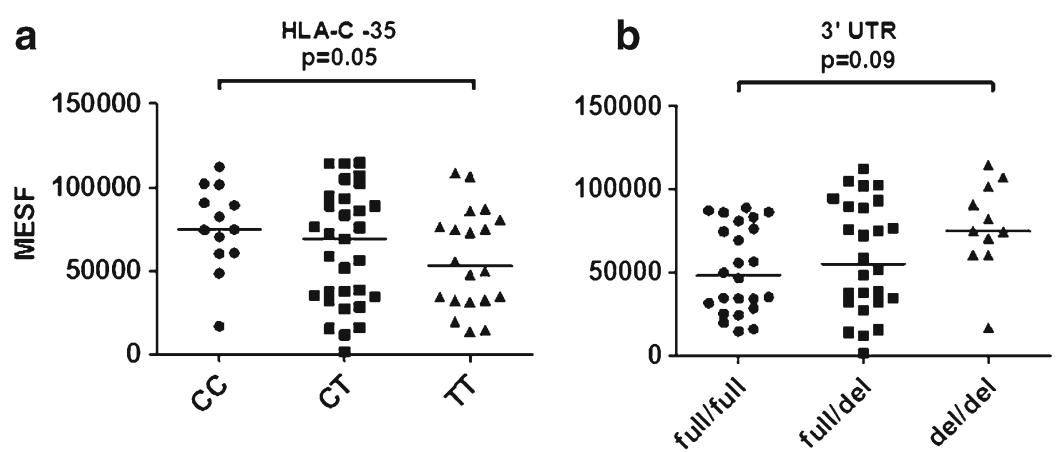

C

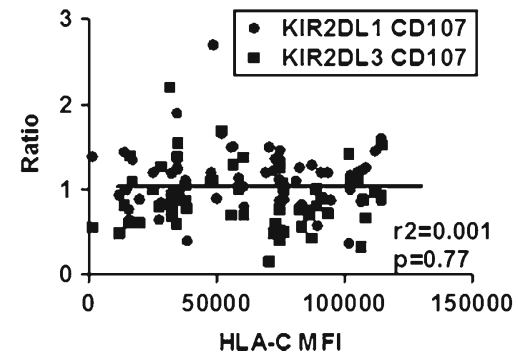

typed by applying a reverse sequence-specific oligonucleotide method according to the manufacturer's instructions (One Lambda Inc., Canoga Park, CA).

\section{Statistics}

Functional and phenotypic NK cell-related characteristics were compared with nonparametric tests (Mann-Whitney $U$ and Kruskal-Wallis). Correlations were assessed by calculating Spearman's rank correlation coefficient. Factors affecting NK cell function were analyzed in a multivariable fashion using generalized linear models. All $p$ values are two-sided and were considered significant if $\leq 0.05$.

\section{Results}

Function of KIR2DL1+ and KIR2DL3+ NK cells is regulated by the number of HLA-C KIR ligands

Phenotypic and functional characteristics of 66 healthy donors were analyzed. At the HLA-C locus, 20 donors (30\%) were homozygous for $\mathrm{C} 1$ ( $\mathrm{C} 1 \mathrm{C} 1), 15$ donors were homozygous for $\mathrm{C} 2$ (C2C2), and the remaining 31 donors were heterozygous (C1C2). All donors in this study carried and expressed the KIR2DL1 gene, and eight donors were negative for KIR2DL3 and were excluded from the analyses focusing on this receptor.

Table 1 Multivariate analysis of factors influencing licensing of KIR2D expressing NK cells

\begin{tabular}{|c|c|c|c|c|c|c|}
\hline & \multicolumn{3}{|l|}{ CD107a } & \multicolumn{3}{|l|}{ IFN- $\gamma$} \\
\hline & Effect size & $95 \% \mathrm{CI}$ & $p$ value & Effect size & $95 \% \mathrm{CI}$ & $p$ value \\
\hline Number of HLA-C ligands & +0.17 & +0.07 to +0.26 & 0.001 & +0.17 & +0.08 to +0.26 & $<0.001$ \\
\hline HLA-C (increase per 10,000 MESF) & -0.002 & -0.02 to +0.02 & 0.85 & -0.01 & -0.04 to +0.01 & 0.26 \\
\hline \multicolumn{7}{|l|}{ HLA-C -35} \\
\hline TT & 0.00 & - & - & 0.00 & - & - \\
\hline $\mathrm{CT}$ & -0.01 & -0.15 to +0.14 & 0.95 & -0.07 & -0.22 to +0.08 & 0.37 \\
\hline $\mathrm{CC}$ & -0.03 & -0.22 to +0.17 & 0.78 & -0.04 & -0.24 to +0.17 & 0.71 \\
\hline \multicolumn{7}{|l|}{ 3' UTR SNP } \\
\hline Non-del/non-del & 0.00 & - & - & 0.00 & - & - \\
\hline Non-del/del & +0.01 & -0.01 to +0.19 & 0.95 & -0.03 & -0.37 to +0.25 & 0.70 \\
\hline Del/del & +0.07 & -0.09 to +0.22 & 0.40 & -0.06 & -0.21 to +0.15 & 0.77 \\
\hline
\end{tabular}




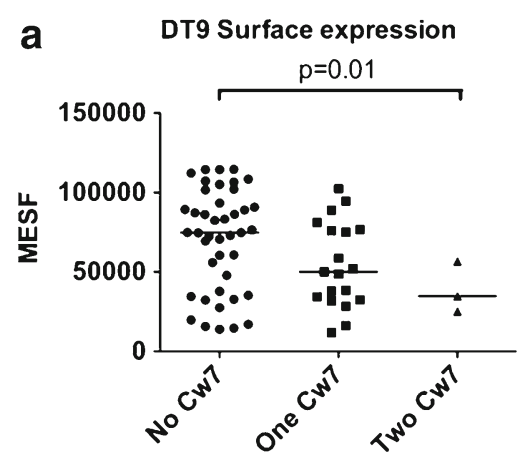

Fig. 5 Correlation of HLA-Cw7 status and cell surface HLA-C quantity and NK cell function. HLA-C surface expression-as measured with the pan-HLA-C antibody DT9-progressively decreases in
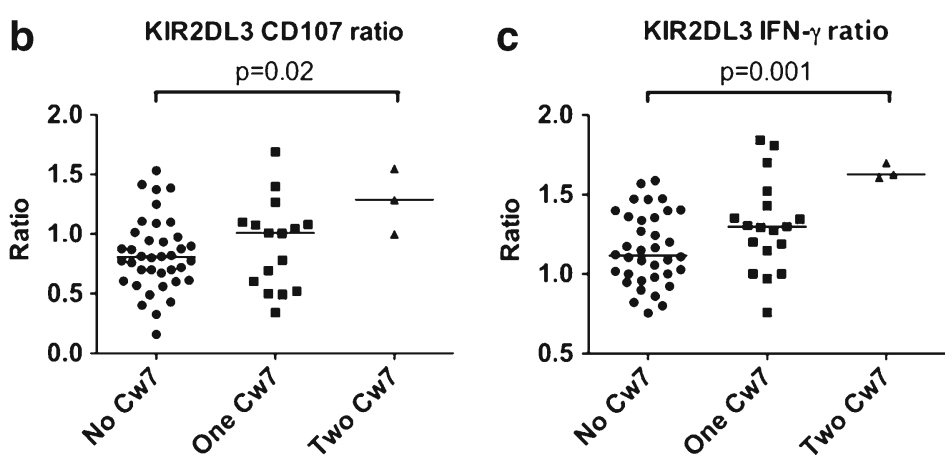

Analysis of NK cell function in correlation with KIR ligand status confirmed and extended previously published data on the functional consequence of co-expression of the inhibitory KIR3DL1 with its ligand, HLA with the Bw4 motif(Kim et al. 2008). Both cytokine production and degranulation significantly increased in NK cells carrying inhibitory KIR2D with HLA-C specificity if the corresponding ligand was present (Fig. 2). KIR2DL1-positive NK cells produced more cytokine and degranulated at higher frequency in donors carrying one or two copies of the KIR2DL1 ligand HLA group C2 (Fig. 2a, b). In contrast, NK cells expressing KIR2DL3 were most functional in donors carrying the $\mathrm{C} 1$ group ligand for this receptor (Fig. 2c, d).

HLA-C-related polymorphisms and quantity of HLA-C do not correlate with NK cell function

At the $H L A-C-35$ SNP locus, 12 donors (18\%) carried two $\mathrm{C}$ alleles (CC), 22 donors (33\%) carried two T alleles (TT), and the remaining 32 donors (49\%) were heterozygous (CT). In univariate analysis, no difference in CD107a expression and IFN- $\gamma$ production of KIR2DL1+ and KIR2DL3+ NK cell subsets were detected between CC, CT, or TT donors (Fig. 3).

We next evaluated HLA-C surface expression with the pan-HLA-C antibody DT9 on lymphoid cells by FACS. In agreement with published data (Thomas et al. 2009), we found a significant correlation between $H L A-C-35$ polymorphism and HLA-C surface expression (Fig. 4a). As expected, correlation of HLA-C surface expression with the 3' UTR SNP showed a trend towards higher surface HLA-C for carriers of the deleted variant; however, this correlation did not reach the level of statistical significance (Fig. 4b). As the quantity of surface HLA-C might affect the licensing process independently from the $H L A-C-35$ and $3^{\prime}$ UTR SNP status, we next correlated NK cell licensing ratios to surface HLA-C quantity. Neither licensing ratios of CD107a degranulation nor IFN- $\gamma$ cytokine production was donors carrying 0 , 1, or $2 \mathrm{HLA}-\mathrm{Cw} 7$ alleles (a). Despite low surface expression, HLC-Cw7 strongly licenses KIR2DL3+ NK cells as assessed by CD107a and IFN- $\gamma$ production (b and $\mathbf{c}$ )

significantly correlated to DT9 expression $\left(r^{2} 0.001, p=0.77\right.$ for CD107a, Fig. $4 c ; r^{2}=0.01, p=0.24$ for IFN- $\gamma$, Fig. 4d).

Finally, we used multivariable generalized linear models to account for potential confounding between variables influencing licensing status. Table 1 shows the results of the analysis accounting for number of HLA-C ligands, HLA-C quantity (DT9 expression), and the HLA-C-related polymorphisms. The only variable significantly influencing NK cell licensing by KIR2DL1 and KIR2DL3 was the number of HLA-C ligands, whereas both HLA-C-related polymorphisms and HLA-C quantity failed to significantly impact NK cell licensing.

HLA-Cw7 strongly licenses KIR2DL3+ NK cells despite being expressed at low quantities at the cell surface

A previous study by Corrah et al. investigating the relationship between $H L A-C-35$ and cell surface HLA-C described low surface expression of HLA-Cw7, but failed to replicate a correlation of $H L A-C-35$ status with surface HLA-C regarding alleles other than $\mathrm{Cw} 7$ (Corrah et al. 2011). We therefore performed HLA-C typing on our cohort, which revealed that 20 donors (30\%) carried one $\mathrm{Cw} 7$ allele, and an additional 3 donors (5\%) carried two HLA-Cw7 alleles (in all cases either $\mathrm{Cw}^{*} 0701$ or $\mathrm{Cw}^{*} 0702$, which are both in linkage disequilibrium with $\mathrm{HLA}-\mathrm{C}-35 \mathrm{~T})$. Correlation of $\mathrm{Cw} 7$ status with cell surface HLA-C quantity showed a dose-dependent reduction of HLA-C quantity with increasing number of HLA-Cw7 alleles (Fig. 5a), thus confirming the data by Corrah et al.. Also in agreement with this study, we found that after exclusion of donors carrying HLA-Cw7 alleles, the $H L A-C-35$ status no longer significantly affected the HLA-C cell surface expression (median MESF 78590, 77797, and 74665, for CC, CT, and TT donors, respectively, $p=0.65$ ).

Despite being expressed at low quantity, HLA-Cw7 proved to strongly license KIR2DL3+ NK cells (Fig. 5b, c). With an average increase per $\mathrm{Cw} 7$ ligand in the 
KIR2DL3 licensing ratios of +0.17 for CD107a and +0.19 for IFN- $\gamma(p=0.02$ and $<0.001), \mathrm{Cw} 7$ licensed KIR2DL3 more strongly than other frequently expressed group $\mathrm{C} 1$ ligands: $\mathrm{Cw} 1+0.12 /+0.07$; $\mathrm{Cw} 3+0.08 /+0.10$, Cw8 0.09/ +0.12 (for CD107a and IFN- $\gamma$, respectively). The strongest KIR2DL1-licensing ligand was HLA-Cw5 $(+0.24 /+0.22$ for $\mathrm{CD} 107 \mathrm{a}$ and IFN- $\gamma$, respectively).

\section{Discussion}

In the present study, we addressed a potential impact of the surface expression quantity of HLA-C on NK cell licensing. We chose to study licensing by KIR2DL1 and KIR2DL3 because these receptors have defined and mutually exclusive ligands and because antibodies to both receptors are available which do not cross-react with the respective counterpart activating KIR. In agreement with previous studies (Anfossi et al. 2006), we show that the HLA-C-specific inhibitory receptors KIR2DL1 and KIR2DL3 confer increased functional capacity to NK cells in donors that carry the respective KIR ligands. Both IFN- $\gamma$ production and degranulation dose-dependently increased with the number of KIR ligands in NK cells expressing KIR2DL1 and KIR2DL3.

No statistically significant effect on NK cell licensing could be attributed to the $H L A-C-35$, the 3' UTR HLA-C polymorphism, or the amount of cell surface HLA-C. One possible explanation for the failure of cell surface HLA to influence the licensing process is that the threshold quantity required for NK cell licensing lies below the level of even low-expressing alleles. Recent studies have estimated the number of HLA-C molecules necessary to inhibit NK cell activation via interaction with KIR2DL1 receptor. These analyses have suggested that inhibition increases with growing number of HLA-C molecules with a saturation threshold at approximately 20,000 molecules/cell, above which inhibition reaches a plateau (Almeida et al. 2011). It is conceivable that a similar threshold exists for the KIR/HLA interaction during the licensing process, and that even low-expressing alleles are expressed at quantities above this threshold.

In agreement with previous data (Thomas et al. 2009), we found a significant correlation of $H L A-C-35$ with the amount of HLA-C as measured by flow cytometry. Another recently published study only partially confirmed the association of $H L A-C-35$ with cell surface HLA-C. Corrah et al. showed in their analysis of $25 \mathrm{HIV}$-infected patients that the correlation of $H L A-C-35$ with cell surface HLA-C quantity was exclusively due to the linkage disequilibrium of HLA-Cw7 with HLA-C -35 T (Corrah et al. 2011). In our population of healthy donors, we confirm that $\mathrm{Cw} 7$ shows significantly lower surface expression than non-Cw7 alleles, but unexpectedly found that HLA-Cw7 more strongly licenses KIR2DL3+ NK cells than any other $\mathrm{C} 1$ group ligand. These data are in agreement with the notion that allelic polymorphism within HLA-C rather than quantity of cell surface expression influences the NK cell licensing process.

An issue that remains unresolved by this study is how homozygosity for class I KIR ligands increases licensing (Elliott and Yokoyama 2011). KIR ligand homozygosity is expected to increase the number of HLA molecules expressed on a cell, but the data shown here suggest that the resulting increased effector capacity might not be due to an increase in quantity of KIR ligands alone. Interestingly, many studies in humans have shown that homozygous presence of KIR ligands is necessary to see licensing effects (Khakoo et al. 2004; Kim et al. 2008), whereas in mouse models heterozygous for the major histocompatibility complex (MHC)-I ligand for a given Ly49 receptor, licensing could be documented (Jonsson et al. 2010). So far, it remains open whether licensing in humans and in mice is differentially regulated regarding the requirement of MHC-I ligand zygosity.

In conclusion, we found no evidence that the HLA-Crelated polymorphisms or quantity of cell surface HLA-C regulates the NK cell licensing process. Regarding the association of $H L A-C-35$ and of the 3' UTR SNP with the course of HIV infection, our data do not support a role of NK cell licensing in the improved disease control of carriers of HLA-C $-35 \mathrm{C}$ alleles or 3' UTR deletion variants. However, a major limitation of this study lies in the facts that experiments were carried out with NK cells derived from healthy donors rather than HIV patients. Chronic HIV infection leads to profound changes in NK cell phenotype and function (Mavilio et al. 2003), which might also affect the licensing process. Alternative explanations to be investigated in the future include an association of $H L A-C-35$ and of $3^{\prime}$ UTR deletion variants with HLA-C alleles endowed with increased function regarding their interaction with CD8 $+\mathrm{T}$ cells, or associations that are completely independent from HLA-C surface expression.

Acknowledgments This study was supported by grants from the Swiss National Science Foundation (grant PPOOP3 128461/1) and by the "Novartis Stiftung für medizinisch-biologische Forschung."

\section{References}

Almeida CR, Ashkenazi A, Shahaf G, Kaplan D, Davis DM, Mehr R (2011) Human NK cells differ more in their KIR2DL1-dependent thresholds for HLA-Cw6-mediated inhibition than in their maximal killing capacity. PLoS One 6:e24927

Alter G, Malenfant JM, Altfeld M (2004) CD107a as a functional marker for the identification of natural killer cell activity. J Immunol Methods 294:15-22

Alter G, Heckerman D, Schneidewind A, Fadda L, Kadie CM, Carlson JM, Oniangue-Ndza C, Martin M, Li B, Khakoo SI, Carrington M, Allen TM, Altfeld M (2011) HIV-1 adaptation to NK-cellmediated immune pressure. Nature 476:96-100

Alves LG, Rajalingam R, Canavez F (2009) A novel real-time PCR method for KIR genotyping. Tissue Antigens 73:188-191 
Anfossi N, Andre P, Guia S, Falk CS, Roetynck S, Stewart CA, Breso V, Frassati C, Reviron D, Middleton D, Romagne F, Ugolini S, Vivier E (2006) Human NK cell education by inhibitory receptors for MHC class I. Immunity 25:331-342

Biassoni R, Cantoni C, Marras D, Giron-Michel J, Falco M, Moretta L, Dimasi N (2003) Human natural killer cell receptors: insights into their molecular function and structure. J Cell Mol Med 7:376-387

Brodin P, Hoglund P (2008) Beyond licensing and disarming: a quantitative view on NK-cell education. Eur J Immunol 38:2934-2937

Corrah TW, Goonetilleke N, Kopycinski J, Deeks SG, Cohen MS, Borrow P, McMichael A, Brackenridge S (2011) Reappraisal of the relationship between the HIV-1-protective single-nucleotide polymorphism 35 kilobases upstream of the HLA-C gene and surface HLA-C expression. J Virol 85:3367-3374

Elliott JM, Yokoyama WM (2011) Unifying concepts of MHC-dependent natural killer cell education. Trends Immunol 32:364-372

Fellay J, Shianna KV, Ge D, Colombo S, Ledergerber B, Weale M, Zhang K, Gumbs C, Castagna A, Cossarizza A, Cozzi-Lepri A, De Luca A, Easterbrook P, Francioli P, Mallal S, Martinez-Picado J, Miro JM, Obel N, Smith JP, Wyniger J, Descombes P, Antonarakis SE, Letvin NL, McMichael AJ, Haynes BF, Telenti A, Goldstein DB (2007) A whole-genome association study of major determinants for host control of HIV-1. Science 317:944-947

Frohn C, Schlenke P, Ebel B, Dannenberg C, Bein G, Kirchner H (1998) DNA typing for natural killer cell inhibiting HLA-Cw groups NK1 and NK2 by PCR-SSP. J Immunol Methods 218:155-160

Jonsson AH, Yang L, Kim S, Taffner SM, Yokoyama WM (2010) Effects of MHC class I alleles on licensing of Ly49A + NK cells. J Immunol 184:3424-3432

Khakoo SI, Thio CL, Martin MP, Brooks CR, Gao X, Astemborski J, Cheng J, Goedert JJ, Vlahov D, Hilgartner M, Cox S, Little AM, Alexander GJ, Cramp ME, O'Brien SJ, Rosenberg WM, Thomas DL, Carrington M (2004) HLA and NK cell inhibitory receptor genes in resolving hepatitis $C$ virus infection. Science 305:872-874

Kim S, Sunwoo JB, Yang L, Choi T, Song YJ, French AR, Vlahiotis A, Piccirillo JF, Cella M, Colonna M, Mohanakumar T, Hsu KC, Dupont B, Yokoyama WM (2008) HLA alleles determine differences in human natural killer cell responsiveness and potency. Proc Natl Acad Sci U S A 105:3053-3058

Kulkarni S, Savan R, Qi Y, Gao X, Yuki Y, Bass SE, Martin MP, Hunt P, Deeks SG, Telenti A, Pereyra F, Goldstein D, Wolinsky S, Walker B, Young HA, Carrington M (2011) Differential microRNA regulation of HLA-C expression and its association with HIV control. Nature 472:495-498
Lanier LL (2005) NK cell recognition. Annu Rev Immunol 23:225-274

Mavilio D, Benjamin J, Daucher M, Lombardo G, Kottilil S, Planta MA, Marcenaro E, Bottino C, Moretta L, Moretta A, Fauci AS (2003) Natural killer cells in HIV-1 infection: dichotomous effects of viremia on inhibitory and activating receptors and their functional correlates. Proc Natl Acad Sci U S A 100:1501115016

Pereyra F, Jia X, McLaren PJ, Telenti A, de Bakker PI, Walker BD, Ripke S, Brumme CJ, Pulit SL, Carrington M, Kadie CM, Carlson JM, Heckerman D, Graham RR, Plenge RM, Deeks SG, Gianniny L, Crawford G, Sullivan J, Gonzalez E, Davies L, Camargo A, Moore JM, Beattie N, Gupta S, Crenshaw A, Burtt NP, Guiducci C, Gupta N, Gao X, Qi Y, Yuki Y, Piechocka-Trocha A, Cutrell E, Rosenberg R, Moss KL, Lemay P, O'Leary J, Schaefer T, Verma P, Toth I, Block B, Baker B, Rothchild A, Lian J, Proudfoot J, Alvino DM, Vine S, Addo MM, Allen TM, Altfeld M, Henn MR, Le Gall S, Streeck H, Haas DW, Kuritzkes DR, Robbins GK, Shafer RW, Gulick RM, Shikuma CM, Haubrich R, Riddler S, Sax PE, Daar ES, Ribaudo HJ, Agan B, Agarwal S, Ahern RL, Allen BL, Altidor S, Altschuler EL, Ambardar S, Anastos K, Anderson B, Anderson V, Andrady U, Antoniskis D, Bangsberg D, Barbaro D, Barrie W, Bartczak J, Barton S, Basden P, Basgoz $\mathrm{N}$, Bazner S, Bellos NC, Benson AM, Berger J, Bernard NF, Bernard AM, Birch C, Bodner SJ, Bolan RK, Boudreaux ET, Bradley M, Braun JF, Brndjar JE, Brown SJ, Brown K, Brown ST et al (2010) The major genetic determinants of HIV-1 control affect HLA class I peptide presentation. Science 330:1551-1557

Thomas R, Apps R, Qi Y, Gao X, Male V, O'HUigin C, O'Connor G, Ge D, Fellay J, Martin JN, Margolick J, Goedert JJ, Buchbinder S, Kirk GD, Martin MP, Telenti A, Deeks SG, Walker BD, Goldstein D, McVicar DW, Moffett A, Carrington M (2009) HLA-C cell surface expression and control of HIV/AIDS correlate with a variant upstream of HLA-C. Nat Genet 41:1290-1294

Winter CC, Long EO (1997) A single amino acid in the p58 killer cell inhibitory receptor controls the ability of natural killer cells to discriminate between the two groups of HLA-C allotypes. J Immunol 158:4026-4028

Winter CC, Gumperz JE, Parham P, Long EO, Wagtmann N (1998) Direct binding and functional transfer of NK cell inhibitory receptors reveal novel patterns of HLA-C allotype recognition. J Immunol 161:571-577

Yokoyama WM, Kim S (2006) Licensing of natural killer cells by self-major histocompatibility complex class I. Immunol Rev 214:143-154 